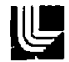

LAWRENCE LIVERMORE LABORATOFY University o' Cahtomia/Livermora, Califomia

CALCULATION OF ROCX FRACTURING FROM MULTIPLE NUCLEAR EXPLOSIVE SOURCES

R. W. Terhune

J. G. Shaw

October 31, 1972

This report was prepared as an account of work eponsored by the Unled Stetes Government, Neither the United States nor the United States Atomic Energy Commission, nor any of their employees, nor any of their contractors, subcontractors, of their employees, makes any warranty, express or implied, or assumes any legal liability or responsibility for the accuracy, com. pleteness or usefulness of any faformation, apparatus, product ar process disclosed, or represents that its use would not intringe privately owned rights.

This paper was prepared for presentation at IAEA Panel on Peaceful Uses of Nuclear Explosives Vienna, Austria, November 30-December 3, 1972

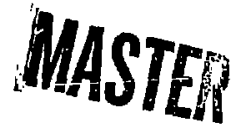




\section{CALCULATION OF ROCK FRACTURING FROM MULTIPLE NUCLEAR EXPLOSIVE SOURCES"}

R. W. Terhune and J. G. Shaw

Lawrence Livermore Laboratory, University of California Livermore, California 94550

\section{REVIEED ABSTRACT}

SOC calculations that agree with experimental measurements of the cavity radii, fracture initiation, and maximum extent of fracturing for the Gasbuggy and Rulison experiments are presented. Most importantly, a criterion is established that relates the number of times a zone in the calculations is fractured, with those regions around the detonalion whore extensive fracturing is observed experimentally. The calculations for both Gasbuggy and Rulison establish that the most distant zone : lat sequentially exceeds the fracture criteria three times is within the chimney or highly fractured reginn. The locations of these zones agree with the maximum distance at which it is necessary to hypothesize a sharp increase in permeability to match data from the gas-production and pressure-buildup tests.

Having established a parameter related to extensive fracturing and permeability enhancement for single explosive sources, we present the first attempts at two-dimensional calculations of multiple explosive sources (detonated both sequentially and simultanously).

Two calculations of effects from sequentially detonated explosives indicate that, if the second explosive were located 5 cavity radi $i$ above the void or free surface created by the detonation of the first explosive, a permeable connection between the two fractured regions is assured

\footnotetext{
Work performed under the auspices of the U.S. Atomic Energy Commission.
} 
This translates to a spacing of 6 cavity radii from a previous explosion in whi ch no chimney is formed, or 8.5 cavity radii from an explosion that produces a chimney height of 3.5 cavity radii. However, if the residual pressure in the lower void remains near overburden pressure, a permeable connection might not be obtained at larger spacings than above.

Three calculations of effects from simultaneously detonated explosives indicate that the interval between the explosives is highly fractured to a radial distance that is more than $50 \%$ greater than that calculated for a single explosive. Also, the calculations indicate that the optimum spacing between such simultaneously detonated explosives is 8 to 10 cavity radii. This preliminary result is surprising, in that spacings required to ensure vertical chimney communication in the simultaneous detonation mode were expected to be smaller than those required for sequential firing. Further work to develop these calculational methods into predictive tools (especially for sequential detonations) is in progress. 


\section{INTRODUCTION}

The work presented in this paper is part of a continuing research program aimed at improving the understanding of effects of nuclear explosives detonated deep underground. Such research is undertaken to make optimun use of such explosives in the development of natural resources.

A basic part of this research effort is the development of models and computational procedures to allow the prediction of effects caused by the detonation of a nuclear explosive, namely, the extent and degree of fracturing, cavity radius, and chimney height. Numerical computer prograns SOC, developed by Cherry and Petersen [1], and TENSOR [2], a two-dimensional version of $S O C$, which simulate the propagation of a stress wave, lave successfully predicted these effects for several nuclear detonations. In their paper, Cherry and Petersen introduced a paraneter (CRK NO.) that counted the number of times a stressed zone exceeded a specified failure criterion, and they suggested that this might provide a measure of the fracture frequency in that zone [1]. They also hypothesized that this parameter could serve as an indicator of rock-permeability enhancement.

Using the SOC and TENSOR numerical mode1s, we first present calculations for two nuclear gas-stimulation experiments, Gasbuggy and Rulison, focusing on the crack number (CRK NO.) as a measuse of the degree and extent of fracturing as compared with the experimentul measurements related to fracture.

The second part of the paper extends these caiculations to multiple nutlear-explosive sources and indicates how the extent and dogree of fracturing is increased for both simultaneous and sequential deconations.

\section{THE NDMEAICAL MODEL}

SOC [1] and TENSOR [2] are numerical computer models of stress-wave propagation of arbitrary amplitude through a Lagrangian grid in one anu two space dimensions, respectively. The most important part of both codes is the rock-mechanics models that attempt to simulate the hydro-elasticplastic behavior of earth meterials subjected to a varying stress field. Reference 1 gives a complete description of the SOC program, together with a comparison of calculations with actual experimental measurements.

The models employ a table relating applied pressure to volume change of a zone for both increasing and decreasing pressures. Also, tables relating the limiting deviatoric stress as a function of pressure for both fractured and unfractured rock are used (failure envelope). The constants relating stress to strain are determined from the slope of the pressurevolume curve and a constant rigidity modulus (or Poisson's ratio). All of the macerial properties used in the model are determined by in situ measurements and laboratory tests on small core samples.

Computation of the parametor of incerest (crack number) is perforned as follows: On each cycle, the calculated deviatoric stress imposed upon the rock is compared to the failure-envelope stress for the unfractured rock at the calculated pressure. For britele fallure, the crack number is set equal to 1 when the calculated shear stress exceeds the failure envelope and a relaxation process is initiated. The relaxation process is assumed to operate until the calculated shear stress is less than half of the limiting shear stress for fractured rock. The shear stress then 
increments normally until it exceeds the failure envelope for the fractured rock, and the relaxation process is again initiated. The crack number is incremented by 1 . Figure 1 shows a computer plot of the shear strass vs the normal pressure for a zone in which the crack number has been incremented throe times.

The published versions of SOC and TENSOR use a scheme dependent on zone size to model relaxation taking place after failure of the rock; consequently, the processus thet lead to incrementing the crack number also depend on the zone size. Zone sizes between 20 to $70 \mathrm{~cm}$ within the expected failure region produce reproducible results, with about a 10 \% variation in the distance at whick a particular crack number occurs. For zones less than $20 \mathrm{~cm}$ in size, instabilities may develop behind the shock front because the relaxation is too rapid, thus increasing the crack number with distance. For zones on the order of $200 \mathrm{~cm}$ or more, the relaxation process is so $51 \mathrm{ow}$ that the zones respond quasielastically and consequently produce very little increnenting of the crack number. All SOC calculations presented in this paper use a 50-cm zone around the source, increasing geometrically with distance such that the maximum zone size in the fracture region is $65 \mathrm{~cm}$. The TENSOR problems are restricted in the number of zones in any one direction because of computer storage limitations; however, carc must be used to ensure that the houndaries are far enough away from the source to avoid reflection problems. This requires the use of zone sizes much larger than those with which we obtain our best results.

When, in a TENSOR calculation, a 50-cm zono around the source is used with tho zone size increasing to $600 \mathrm{~cm}$ at the problem boundaries, calculated results are within 10 of of those obtained from the finer-zoned SOC code. However, this general observation does not hold true for the crack number. The TENSOR zone size within tho fracture region varies between 50 to $150 \mathrm{~cm}$, and these larger zones severely retard the incrementing of tho erack number, as compared with the analogous calculation as carried out on the SOC code. Thus, SOC is used to predict the absolute magnitude and range of shock-induced effects from a detonation, while TENSOR is used to determine relative spatial effects caused by the twodimenstonal requirements of a problem.

\section{CALCULATION OF SINGLE-SOURCE NUCLEAR EXPLOSION EXPERIMENTS}

In this section, we present recent SOC calculations for both the Gasbuggy and Rulison gas-stimulations experiments. The results of these calculations are then compared with experimental data related to rock fracturing. In Fig. 2, the fatlure envelopes [3] used for these calculations are shown. The shear-stress limits for fractured rock (not shown) are a linear relationship between zero prossuro and the brittle ductile point $(B / D)$. Figure 3 shows the loading and unlonding compressibility curves used in the calculations. Poisson's ratio is measured as a function of pressure by one-dimensional strain tests. For sandstones, it varies between 0.1 at zero prossure to 0.4 at $5-\mathrm{kb}$ pressure. The best calculational results are obtained using a value of 0.2 for Poisson's ratio.

\subsection{Gasbuggy}

Gasbuggy [4] was a gas-stimulation experiment using a single nuclear explosive with a nominal yield of $29 \mathrm{kt}$. The explosive was detonated at a 


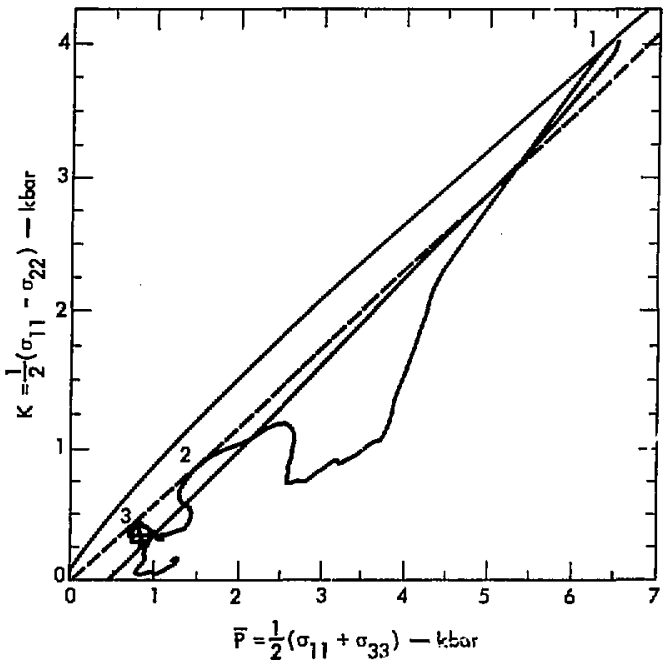

Fig. 1. Shear stress ys normal stress, for zone failing three times. 


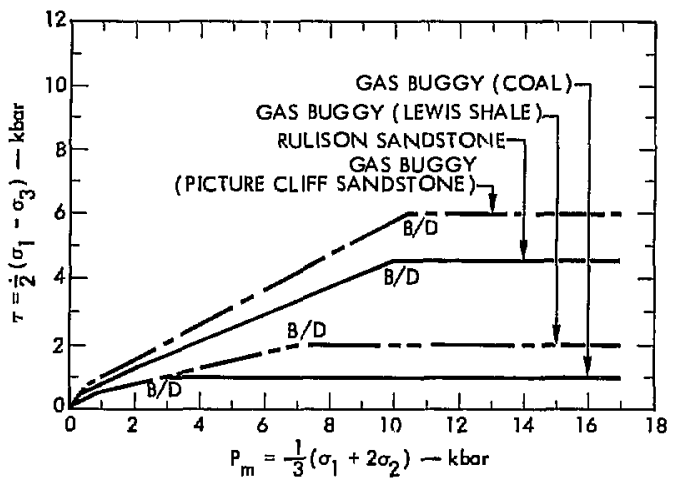

Fig. 2. Failure envelopes for Gasbuggy and Rulison. 


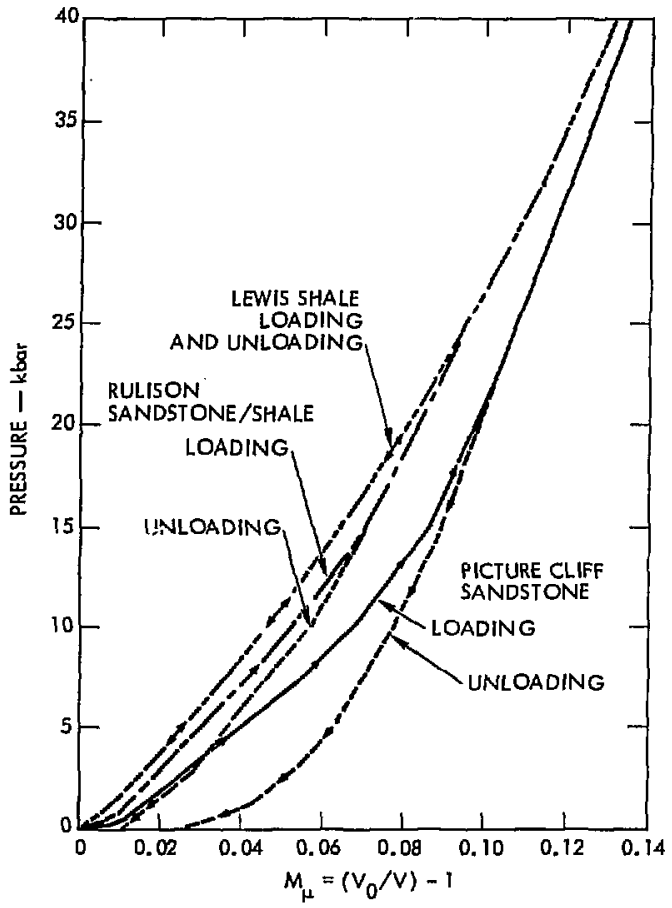

Fig. 3. Compressibility curves for Rulison and Gasbuggy. 
depth of $1280 \mathrm{~m}$ in a Lewis shale formation, $12 \mathrm{~m}$ below the gaswbearing Pictured liffs sandstone formation. A soft low-density conl 1 ayer existed from 100 to $112 \mathrm{~m}$ above the detonation point.

The resules of a vertical SOC calculation using the material properties described is shown in Figs. 4 and 5.

The calculated cavity radius is in excellent agreenent with the inferred civity radius of $24.5 \mathrm{~m}$. The low shear strength of the lewis shale essentially controlled the growth of the cavity. A cavity radius of $21.5 \mathrm{~m}$ would have been predicted for a detonation in the Pictured cliffs sandstone. Based on calculations that matched the experimental data from the nuclear experiments in Hoggar granite [5] and also for Hardhat and Piledriver [1], there seems to bo a correlation between the maximum extent of fallure on compression and the limit of chimney growth. This correlation applied to Gasbuggy would yiold chimney height of approximately $70 \mathrm{~m}$. The measured chimney height of $100 \mathrm{~m}$ was probably the result of the reflection of the shock wave from the coal layer.

The rasults of caliper log measurements 16$]$ on the GB-2-RS wellbare (100 $\mathrm{m}$ from the emplacement hole) are shown in Fig. 4 for both preshot and postshot conditions; these results indicate that the height above the coal layer where damage to the well is indicated is in good agreement with the calculated maximum excent of fracture. Also, the casing broaks observed upon reontry of the emplacement lole agree with these calculations.

More significanc, however, is the measurement of fracture initiation by a cliper cable in GB-1, which was $46 \mathrm{~m}$ northwest of the emplacement we11 [7]. As the shock wave crushed this cable, continuous measurements of tho length of the unfractured cable were taken as a function of time. Figure 5 shows the results of these measurements compared with the calculated fracture intelation distance. While the calculation is sligluty less than the measured value, the agreement with the maximum extent of fracturing is excellent.

These calculations differ from those presented by Cherry and Petersen in Ref, 1 because of the difference in the initial conditions assumed. Cherry and Petersen used yield of $25 \mathrm{kt}$ instead of $29 \mathrm{kt}$. Also, a complete measurement of the material properties has led to the usc of a failure envelope and Poisson's ratio different from those used by Cherry.

\subsection{Rulison}

The Rulison stimulation experinent used a 43-kt explosive detorated at a depth of $2530 \mathrm{~m}$ in an interbedded sandstono-shale formation. The rock was less porous and more ductile and had a lower shear strength than did the Pictured Cliffs sandstone. All postshot data were obtained from a single reentry weIl.

Figure 6 shows the results of the Rulison vertical 50C cnlculation. The Rulison postshot investigation [8] obtained data consistent with a cavity radius of $23.2 \mathrm{~m}$; the caleulations are in excellent agreenent $w 1$ th this number. Also, during the drilling of the reentry well, there was a significant loss of drilling fluid $84 \mathrm{~m}$ above the detonation point, which corresponds to the calculated limit of compressive shear failure. The drilling operation continued to lose fluid to a point $60 \mathrm{~m}$ above the 


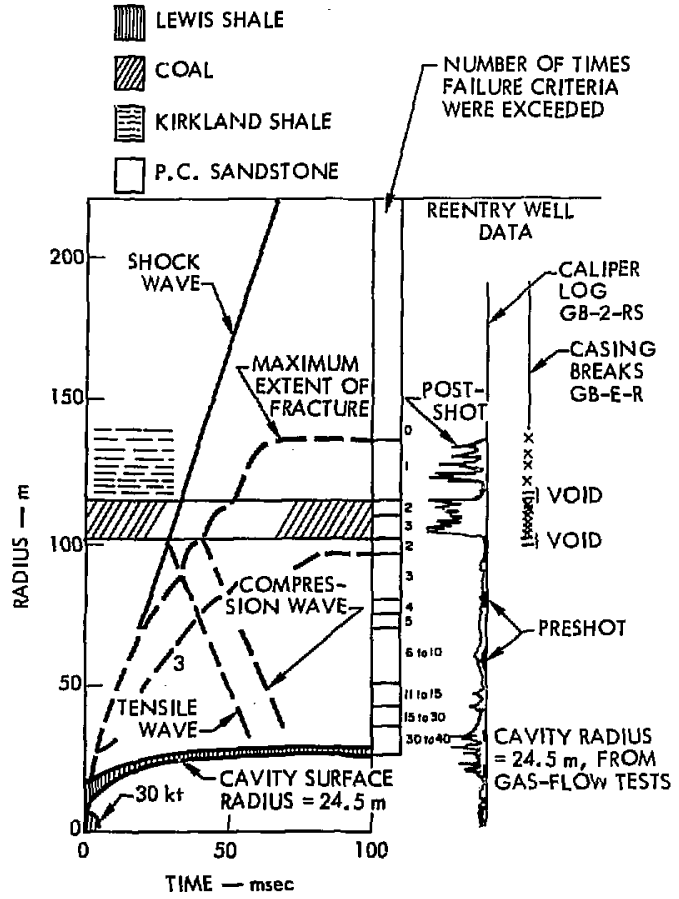

Fig. 4. SOC calculation of Gasbuggy vertical data. 


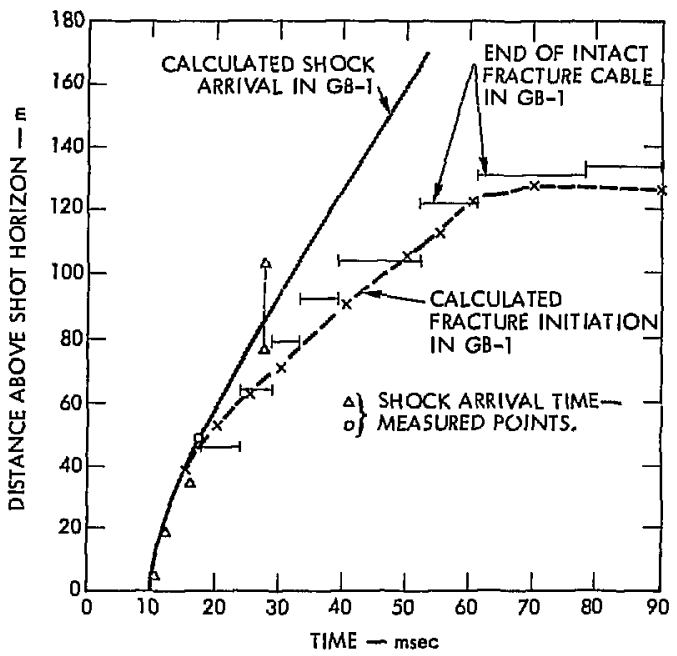

Fig. 5. Shock and fracture in Hole GB-1, $45.7 \mathrm{~m}$ fram emplaciment hole. Triangles represent less-certain data for times of arrival. 


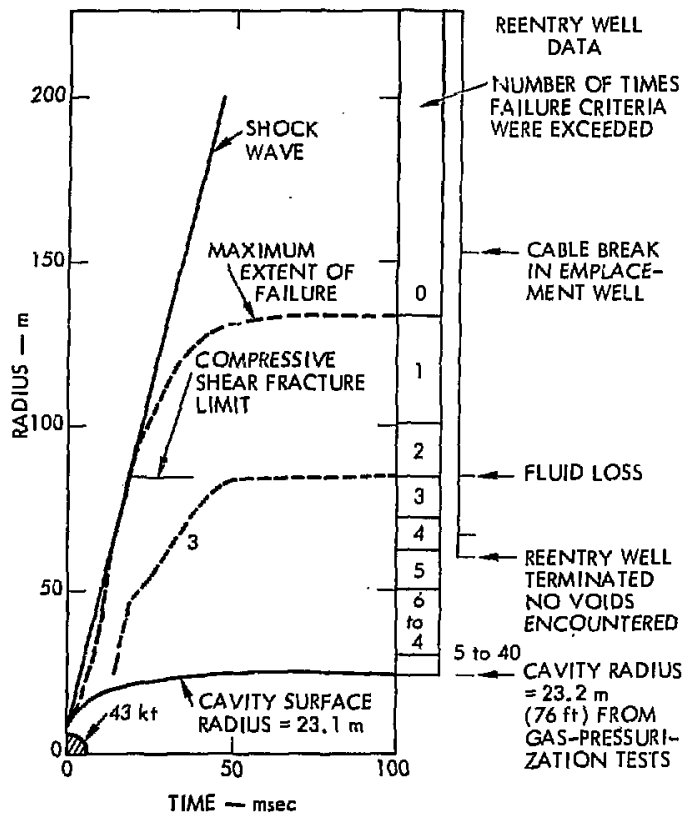

Fig. 6. SOC calculation of Rulison vertical data. 
detonation point, where the well was terminated. No apical voids were encountered. On the basis of the cillculation, a chimney height of $84 \mathrm{~m}$ would have been predicted.

\subsection{Summaty}

The experimental data from Gasbuggy and Rulison confirti that a consisteri application of the SOC progran can accurately predict cavity radij, fracture initiation, and the maximum extent of fracturing. However, a meaningful test of the theory that the maximum init of compressive failure is related to the chimney height is not possible from Gasbuggy data because of the effects of the coal layer. Also, data fron the Rulison re-entry hole are insuffictent for such confinmation, since it is not clear whether the first fluid loss occurred in the chimney proper or in highly fractured rock outside the chimey. In either case, the calculated limits of comprassive failure does agree with the point where the rock has undergone significant fracturing.

'he calculated variation of the crack number with distance is quite different for tho Gasbuggy and Rulison experiments. For Gasbuggy, the crack number decreases relatively smoothly with distance, whereas in the Rulison caleulation the crack number likewise decreased to a distance of 5 in fron the cavity but then remained essentially constant to $70 \mathrm{~m}$ (see Figs, 4 and 6). However, both ealculations are consistont in that in the chinney (or highly fracturad region) the crack number is three or greater and where the crack number is equal to one, no significant changes in the properties of the rock were detected.

\section{CALCULATION OF NILLTIPLE NUCLEAR EXPLOSIVE SOURCES}

The term "multiple explosive sources," as used in this paper, means two or more nuclear explosives emplaced in the same well bore, spaced 5 or more cavity radii apart, and datonated oither sequentially or simultaneous 1 y. The obfect of detonating the explosives in this configuration is to form a continuous permeable region through a several-thousand-meter vertical interval in a natural gas reservoir. Two such experiments are now contemplated for the future. Wagan Wheel, as presently planned, is to utilize five 100-kt nuclear explosives, detonated sequentially, to stimulate a gas reservolr between tho depths of 2400 to $3600 \mathrm{~m}$. Rio Blanco is planned to use three 30-kt nuclear explosives detonated simul tqneously to stimulate a gas reservoir between the depths of 1700 to $2100 \mathrm{~m}$.

The first step in evaluating the potential economic benefit of such experiments is to determine the effects on the surrounding rock caused by the detonation of the explosives. Terhune [5] presented the numerical calculations for a single explosive at the Wagon theel site and estimated the effect of sequential detonations, based on cratering experience. The effect of the overburden pressuro plus the chimey or cavity pressure caused by the first detonation, however, was not rigorously considered.

In this section we present results from a number of calculations simulating the effects from both sequentially and simultanoously detonated nuclear explosions. First, we discuss two TENSOR calculations in which the stress wave from an uppar explosive is reflected from a cavity containing a gas at two different pressures. The overburden pressure as a 
function of vertical distance is simulated to represent the lithostatic pressure at the depth of explosive emplacement $(1830 \mathrm{~m})$. Secondly, results from three TENSOR calculations simulating simultaneous detonations at throe different spacings are presented. All calculations - both for the sequential and simultaneous detonation modes - assume $30 \mathrm{kt}$ as the energysource term for each oxplosive; also, the material properties determined for the Wagon Wheel site $[5,9]$ are used, with the following exceptions:

- The maximum failure criterion for shear failure is $7.5 \mathrm{~kb}$ instead of $15 \mathrm{~kb}$.

- A 17 permanent compaction is allowed on compression when the applied stress is greater than $15 \mathrm{~kb}$.

- The brittle/ductile transition point is $12 \mathrm{~kb}$ rather than $30 \mathrm{~kb}$.

4.1. One-dimensional SOC calculations: criterion for rock fracturing

As previously mentioned, the predictive capability for the degree of rock fracture is somewhat sensitive to zoning. Figure 7 shows the results of 5OC and TENSOR calculations, comparing the crack numbers cbtained from both SOC and TENSOR. Both problems have the same zone size at the source boundary, but, starting at $100 \mathrm{~m}$ from the source, the TENSOR proilem has zones three times as large as the SOC zones. The agreement between the shock position, limit of initial fracture, and cavity radius is good, but the effect of zone size on the czack number is notable.

The material properties used for these calculations assume lesscompressible rock with higher strength than either the Gasbuggy or Rulison sandstone. Yet the limit of compressive fallure agrees with the distance to a crack number of 3 (which is similar to the Rulison results), while the variation in the crack number with distance is similar in distribution to that calculated for the Gasbuggy experiment.

For Gasbuggy, it was established that those zones with CRK NO. $\geq 3$ were all in the chimney region, while crack numbers equal to 1 were not. Likewise, for Pulison, the CRK ND. $\geq 3$ were either in the chimney or in the highiy fractured permeable region surrounding the chimney, whereas CRK No. = 1 were not.

Thus, it seems reasonable to assume that large permeability enhancements will be produced in these regions where the SOC code predicts that CRK NO. $\geq 3$. If it is then assumed that two nuclear explosives were spaced such that the calculated limit where CRK NO. = 3 for each detonation wert found to overlap, then it might be concluded that there would be a permeable connection between the two fractured regions. Because of the larger zoning required for a TENSOR calculation, this region is not as well defined as it is in the SOC calculation. In fact, the crack number values calculated by TENSOR are approximately half of those determined by SOC at the same distance and with other input parameters the same for both calculations. On this basis, it seems that using the CRK NO. $\geq 2$ as the linit of extensive fracturing and perzenbility increase is an appropriately conservative assumption. 


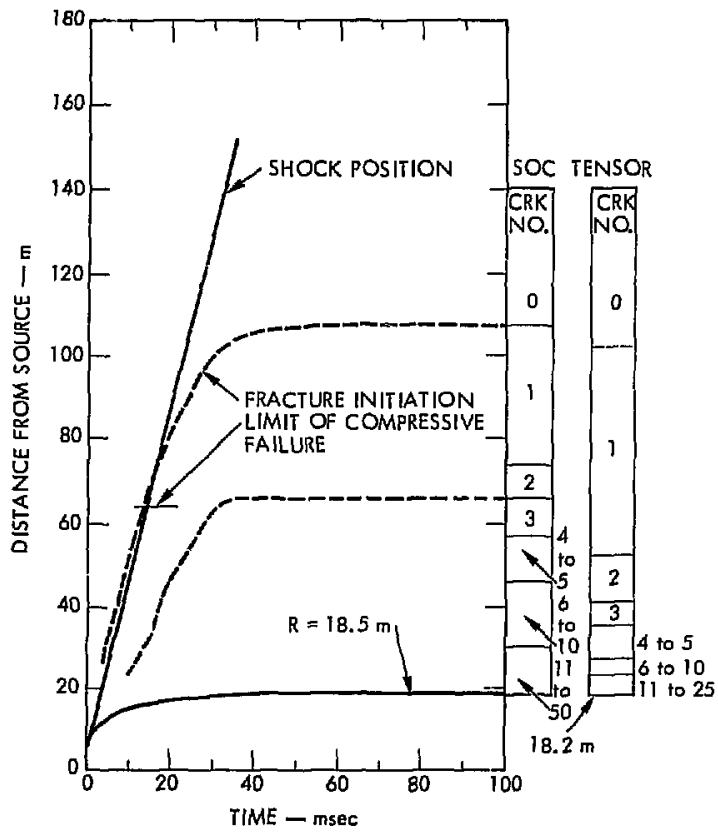

F1g. 7. One-dimensionsl spherical calculation for 30-kt explosive yield at depth of $1830 \mathrm{~m}$. CRK No. is the number of times that fallure criteria have been exceeded. 
When the first explosive of a sequentially fired array is detoreted, a fracture pattern around the detonation point is formed, similar to that indicated in Fig. B. Ne assume that, at some distance above this detonation point, a void will have been created. This void will be located somewhere between the original cavity surface (prior to chimney formation) and the maximum distance at which the rock undergoes compressive failure. This void may be the cavity itself, but is more likely to be the top of either a fully or partially formed chimney. The pressure in the void can be assumed to be somewhere hetween the overburden pressure and about half of the pressure existing in the gas reservoir.

The primary purpose of this computational modeling approach is to ascertain the optimum distance between explosives such that a permeability connection is assured between the two fractured regions. In the caurse of this work, the effect of the void pressure and the overburden pressure must be determined. Also, the amount of fracture enhancement by the second detonation in the already-fractured region surrounding the first detonation point should be ascertained.

The calculations presented here represent the initial step in an effort to answer these questions. The simplified but conservative assumptions used in these calculations are as follows:

o The second explosive is 5 cavity radii above the top of the void. This represents a possible spacing of between $6 R_{c}$ (if it is assumed that no chimney is formed) to as much as $8.5 R_{c}$ (based on a chimley height of $3.5 R_{c}$ resulting from the first detonation). calculation.

- The pressure within the void remains constant during the

- The existence of the fractured and stressed region around the first detonation is ignored and the rock is assumed to have its original strength.

o The initial stress stare of the rock is consigtent with the lithostatic $\Gamma^{-a s s u r e ~ b e t w e e n ~ t h e ~ d e p t h s ~ o f ~} 1530$ to $2130 \mathrm{n}$.

o The explosive yield is assumed to be jo kt, and the sequence of explosions is assuned to be from bottom to top.

The boundaries of the grid used in the TENSOR calculation form a cylinder that is $600 \mathrm{~m}$ high and $300 \mathrm{~m}$ in radius; the relative positions of the second detonation point and the void resulting from the first explosion can be seen in Fig. B. The shock wave reaches the boundnries of the problem 72 msec after the second detonation, and the problem is terminated when the reflected wave begins to approach the vojd. Note that the primary shock wave reachas the top of the void at $20 \mathrm{msec}$.

The void pressure for the first problem is set at $463 \mathrm{~b}$. Figure 8 shows a computer plot of the spatial distribution of the crack numbers at $92.6 \mathrm{msec}$. The total downward displacement at the upper surface of the vold at this time was $0.9 \mathrm{~m}$ (from an initial $94.5 \mathrm{~m}$ to $95.4 \mathrm{~m}$ ). The augmented rock fracturing above the vold that is caused by the shock wave 


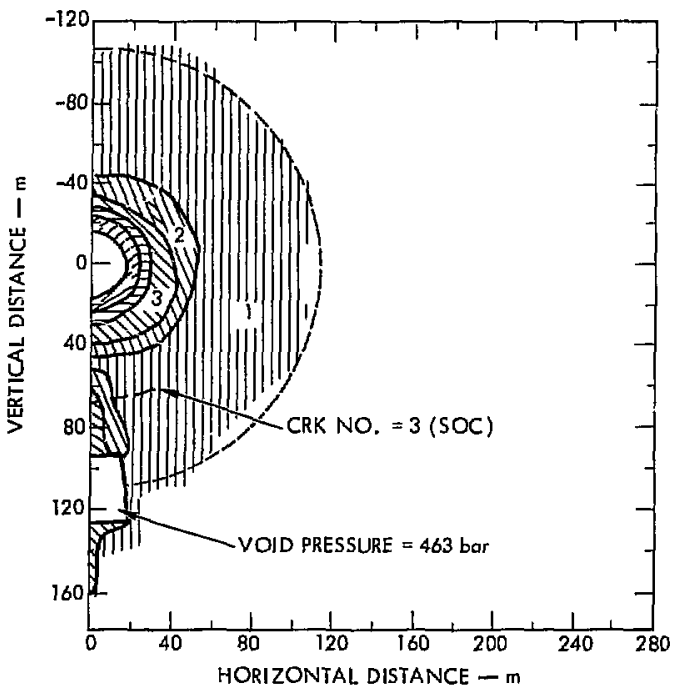

Fig. B. Snatial distribution of crack number (CRK ND.) for sequential detonation, with void pressure of 463 bar. 
reflected from the void doss not connect with the CRK NO. = 2, as calculated by TENSOR, around the second detonation point but does intersect the CRX NO. 3 line, as calculated by SOC.

Figure 9 shows a computer plot of the pressures that exist in the region between the carity and the void at $92.6 \mathrm{msec}$. 1 There is a sharp pressure gradient between 50 and $55 \mathrm{~m}$ corresponding to the distance beyond which augmented fracturing did not take place. Whille the pressures above the void are generally lower than those at corresponding locations in other parts of the grid, these pressures are essentially equal to or greater than the initial overburden pressure. If the pressure in the void were loiered at this time, collapse of the cracked region around the second detonation into the l-wer void would most certainly occur.

The second sequential detonation calculation is identical to the first except that the void pressure is reduced to $110 \mathrm{~b}$, to represent a pressure approxinately half that of a typical reservoir. Figure 10 shows the degree of fracturing in the region around the secondudetonation cavity and the first-chimney void. The rarefaction wave reflected fron the void is sufficiently strong to conncct the fractured regions around the cavity with the void. The total downtward displacement at $89 \mathrm{msec}$ at the top of the void is $3.6 \mathrm{~m}$; this displacement is increasing with a velocity of $28 \mathrm{~m} / \mathrm{sec}$. The larger velocities and displacements in this calculation, as compared to the first calculations, have led to the development of a shear zone as indicated in Fig. 10.

The pressures at $89 \mathrm{msec}$ in the region between the cavity and the void are shown in Fig. 11. The unshaded region is at zero pressure, and the zones within this region are expanding. The model allows the rock to bulk, and thus any recompaction causes a slight increase in pressure. The zones above the void that are shaded with vertical lines are beginning to recompact and have pressures 1 ess than $100 \mathrm{~b}$. Most zones in this region have bulked 5 to $10^{\mathrm{s}}$, with some as high as $30 \mathrm{z}$.

In Fig. 11, the 0.5-kb isobar 13ne surrounding the spailed region above the void outlines the shear zone shown in Fig. 10 and indicates the limit of the effects caused by the presence of the void. The relatively large stress gradients that exist in the upper part of this spalled region suggest that in time a highly fractured and bulked cylindrical region, approxinately 20 to $27 \mathrm{~m}$ in radius, would connect the cavity with the void,

Figure 12 shows the particle velacity as $a$ function of time for a point $30 \mathrm{~m}$ ahove the void, $64.5 \mathrm{~m}$ from the detonation point. Results from the two problems just presented are compared to data from a third caleulam tion: this pird calculation is identical to the flrst two, with the exception that the absence of a void has been assumed. In both of the void problens, the rarefaction waves initially increased the particle velocity ubout $9 \mathrm{~m} / 5 \mathrm{sec}$ above that calculated in the problen where no void was present. The limitad crtert of the rarefaction waves in the horizontal direction and the effect of the overburden iressure degrade the volocities

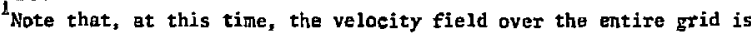
essentidliy zero.
} 


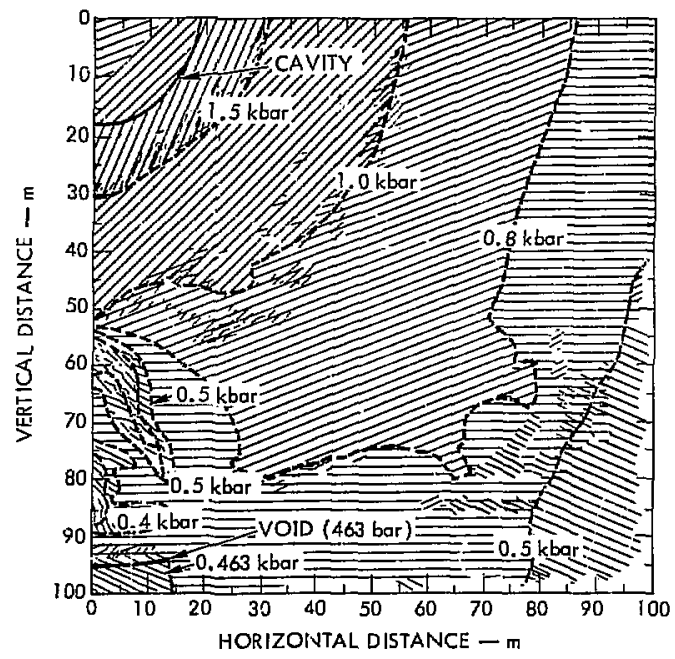

Fig. 9. Isobar map at $\mathbf{9 2 . 6}$ msec for sequential detonation. Vold pressure is 463 bar. 


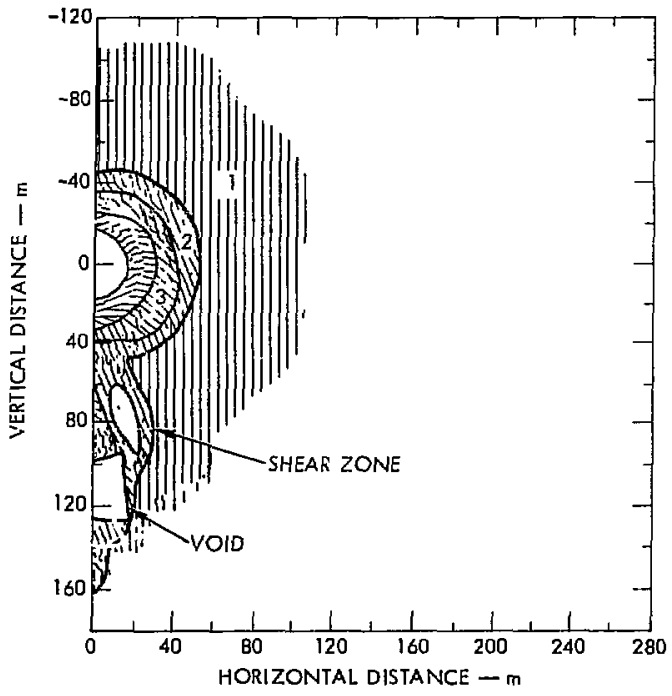

Fig. 10. Spatial distribution of crack number for sequential detonation, with void pressure of 110 bar. 


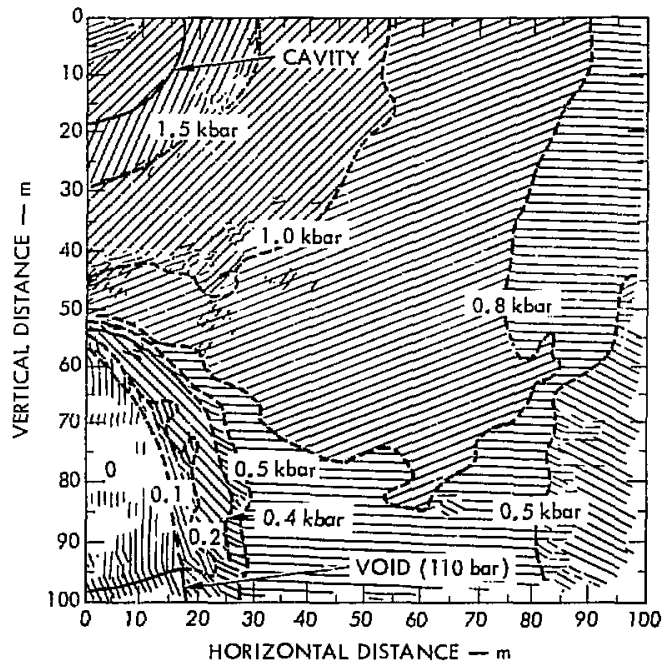

Fig. 11. Isobar map at $89.3 \mathrm{msec}$ for sequential detonation. Void pressure is 110 bar. 


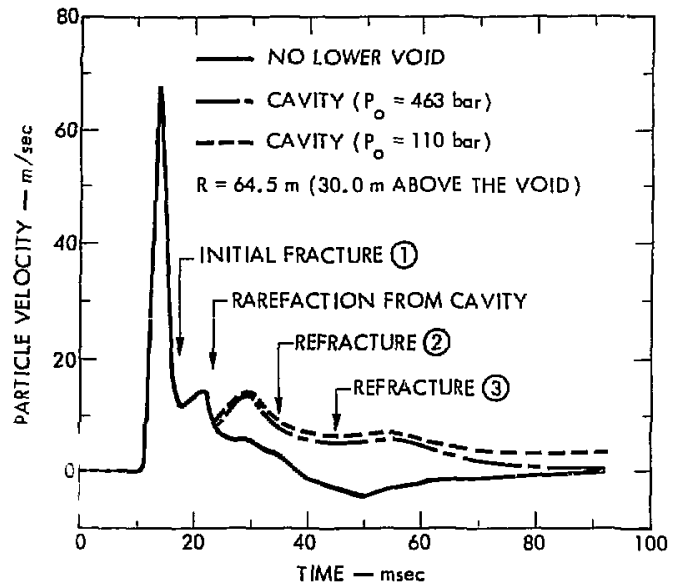

Fig. 12. Particle velocity vs time, for sequential detonation, 
slowly. The effect of the void pressure for a point this far from the vaid is small initially but grows steadily with time. In the problem where the initial void pressure is $465 \mathrm{~b}$, this region has essentially comc to rest at 92 msec. In the second problem, however, where the void pressure is $110 \mathrm{~b}$, the same region considered at $92 \mathrm{mscc}$ has a velocity of $3.5 \mathrm{~m} / \mathrm{sec}$. Thus, the initial void pressure has a rather small effect at relatively early times, but the effect at later times indicates that, if the void pressure should remain high during the time of jnterest, the extent of the connection between the void and the fractured region surrounding the second detonation could be questionable at spacings larger than those assumed for this calculation.

\subsection{Simultaneous detonations}

"Simultaneous" detonations, as used here, means that the nuclear axplosives are fired within a millisecond of each other. The shock waves from the two explosives will meet at the midpoint between them. The simul taneous detonations axe simulated in TEN.OOR by placing a plane of symmetry above an explosive source. The boundary conditions at this plane allow only tangential motion, thus effectively producing a mirror image of the explosive source on the other side of the plane. The principal object of these calculations was to determine the extent of the fracture enlarcement caused by the interaction of the shock waves from two explosives.

The grid is a cylinder $300 \mathrm{~m}$ in radius, with the dotonation point $\mathrm{a}$ variable distance from the plane of symmetry and $300 \mathrm{~m}$ above tho bottom of the grid. As previously noted, this set of calculations used the same yield of $30 \mathrm{kt}$ and material properties as were used for the stquential calculations.

The first calculation simulates a spacing of 5 cavity radi $i$, placing the plane of symmetry 2.5 cavity radii or $46 \mathrm{~m}$ above the detonation point. The overburden pressure at the plane of symmetry is $440 \mathrm{~b}$ and increases appropriately with depth. The peak pressure as the shock reaches the interface at about 9 msec is $11 \mathrm{~kb}$, increasing to $21 \mathrm{~kb}$ as the shock is reflected. The zones along the interface are severely distarted with the large horizontal displacement that results from the flow of material along the interface. The horizontal flow is so severe that a region along the axis of symmetry near the interface maintains a zero pressure from about 18 to 25 msec, which allows the cavity to expand preferentially coward the interface during this time interval. The velocity and pressuro gradient seem to stablize at $45 \mathrm{msec}$ without further refracturing occurring. The problem is terminated at $50 \mathrm{msec}$. Figure 13 shows the degree of fracturing indicated by the crack number at this time. In the region between the interface and the cavity, there is a 50 to $70 \%$ increase in the horizontal extent of all degrees of fracturing. There is a break in the region for CRK NO. = 2 that would probably not exist if the TENSOR zoning were smaller. Ignoring this break would extend $C_{R K}$ NO. $=2$ to about $150 \mathrm{~m}$ horizontally. Since, in TENSOR, CRK NO, $=2$ corresponds to CRK NO. $=4 / 5$ in SOC, multiple nuclear explosives with a spacing of 5 cavity radii could produce as much as $a 180$ increase in the radius of the highly fractured region lying betwoen the detonation poines.

For the next calculation, the distance between the Interface and the detonation point is increased to $74 \mathrm{~m}$, equivalent to a spacing af 8 cavity radii between explosives. The pressure at the shock front as it reaches the interface at $16 \mathrm{msec}$ is $3.5 \mathrm{~kb}$. This pressure doubles to $7 \mathrm{~kb}$ upon 


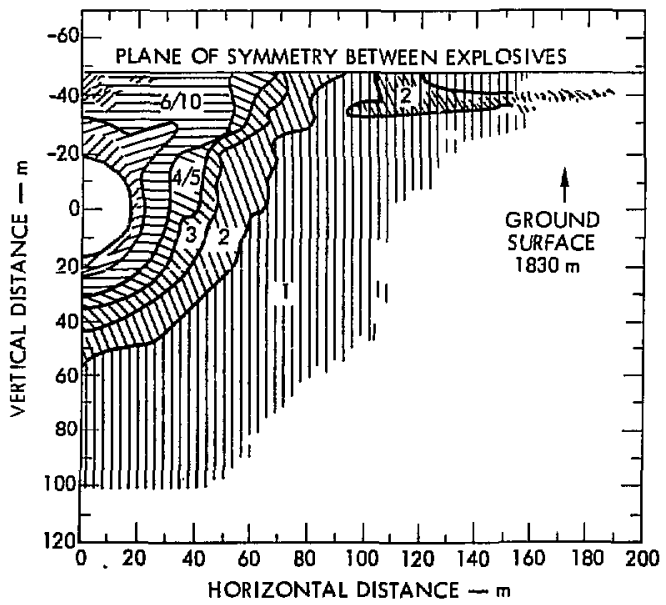

Fig. 13. Degree of fracture for simul taneous detonations spaced five cavity radii apart. 
reflection of the shock wave. Figure 14 shaws the spatial distribution of the crack nubber for this calculation. The fracturing is notably less severe between the interface and the cavity than for the $5 R_{c}$ calculation. The regions defined by $C I K$ NO. $=6 / 10$ and CRK NO. $=4 / 5$ are slightly increased vertically, but are not increased horizontally. For CRK No. $=3$, the entire region between the interface and the top of the cavity is extended out to $70 \mathrm{~m}$. This is an increase of $60 \%$ in horizontal distance for the simultaneous detonation, as compared with a single detonation. As in the $5 \mathrm{n}$ calculation, there is a break in the CRK NO. $=2$ region near the interface at about $90 \mathrm{~m}$ from the vertical axis of symmetry. Even when the additional fracturing between 100 to $140 \mathrm{~m}$ along the interface is not taken into account, multiple detonations at this spacing appear to produce a $60^{\circ}$ increase in the radius of cracked rock throughout the entire vertical region between the cavities.

For the next calculation, we increased the spacing to 10 cavity radii, with the interface $92 \mathrm{~m}$ above the detonation point. Also, the zoning in the lower half of the problem was made spherically symetric instead of rectangular as was the case in the two previous problems. In addition, 15 zones have been added in the radial direction, thus using the maximum number of zanes that the grogram can accomodate.

The shock arrives at the interface $20 \mathrm{~ms}$ after detonation, with a peak pressure of $2.7 \mathrm{~kb}$; once again this pressure is doubled on the reflection of the shock wave. With the spherical zoning used in this problem, the ragged fracture pattern that appeared in the previous culculations disappear; and, with the slightly smaller zoning, the fracturing radius increases to $110 \mathrm{~m}$. Fracturing at the interface is loss sovere than noted in the previous calculations, where pockets of CRK NO, $=3$ appeared in the middle of the larger region of CKK NO. $=2$. In the present calculation, anly the CRK NO. = 2 region reaches the intorface; howcver, this region extends horizontally to a radius of $100 \mathrm{~m}$ and reaches $50 \mathrm{~m}$ below the interface (as shown in Fig. 15).

Figures 16, 17 and 18 show a comparison between the throe culculations on the spacial extent of fracture for CRK NO. $=1,2$, and 3 , respectivoly.

Figure 16 shows the maximum extent of fracture (CRK NO. = 1) for the three calculations; the total volume of rock fractured was essentialiy constant for all three cases, as noted in the following table:

\begin{tabular}{|c|c|}
\hline \multicolumn{2}{|c|}{ CRX NO. = 1} \\
\hline EXPLOSIVE & VOLLNE OF \\
\hline SPACING & FRACIURED ROCK \\
\hline $5 \mathbf{R}_{\mathbf{c}}$ & $3.0 \times 10^{6} \mathrm{~m}^{3}$ \\
\hline $8 \mathrm{Re}_{\mathrm{c}}$ & $3.2 \times 10^{6} \mathrm{~m}^{3}$ \\
\hline $10 R_{c}$ & $3.5 \times 10^{6} \mathrm{~m}^{3}$ \\
\hline
\end{tabular}

Figure 17 shows that, for CRK NO. a 2, which in TENSOR should correspond to a highly fractured rock, the horizontal region characterized by this value is approximately the same for both the $8 R_{c}$ and the $5 R_{c}$ calculations. However, when the volumes of rock enclosed by the CRK NO. a 2 ine 


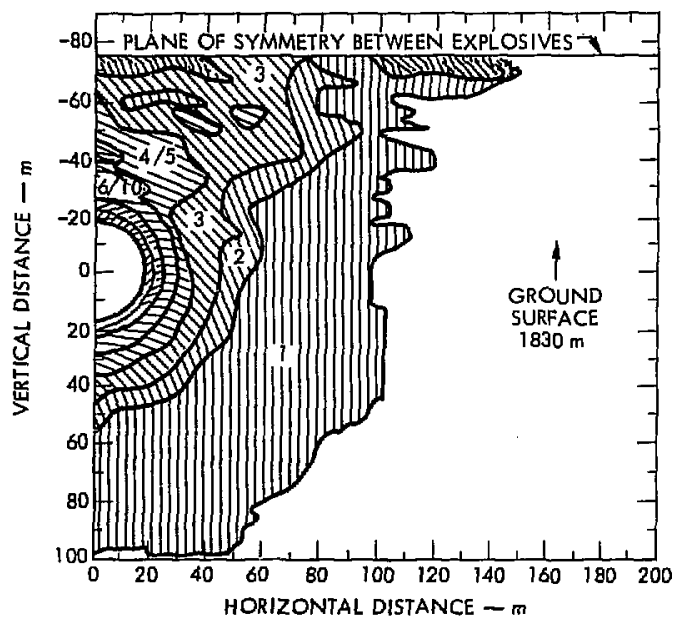

Fig. 14. Degree of fracture for simultaneous detonations spaced eight cavity radii aparî. 


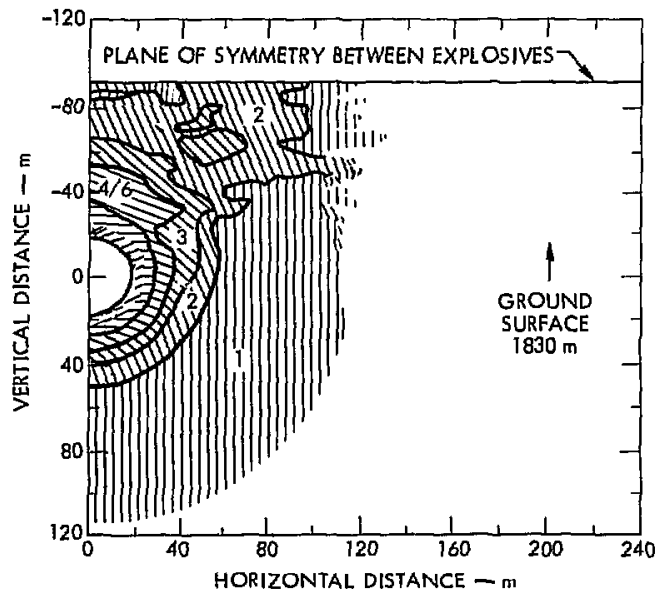

Fig. 15. Degree of fracture for simultaneous detonations spacod I0 cavity radit apart. 


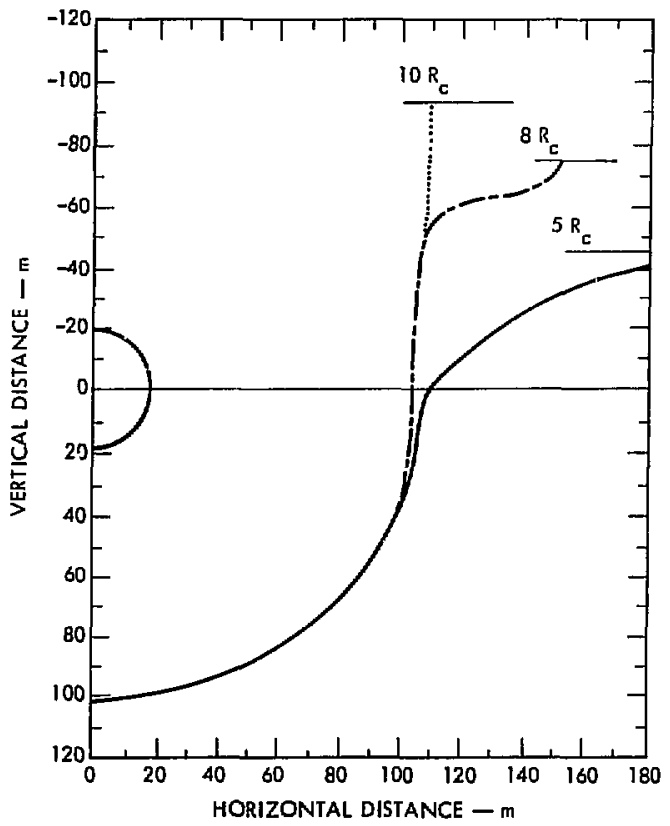

Fig. 16. Distribution of fracture as functions of spacing for simultaneous detorations, with CRK ND. $\geq 1$. 


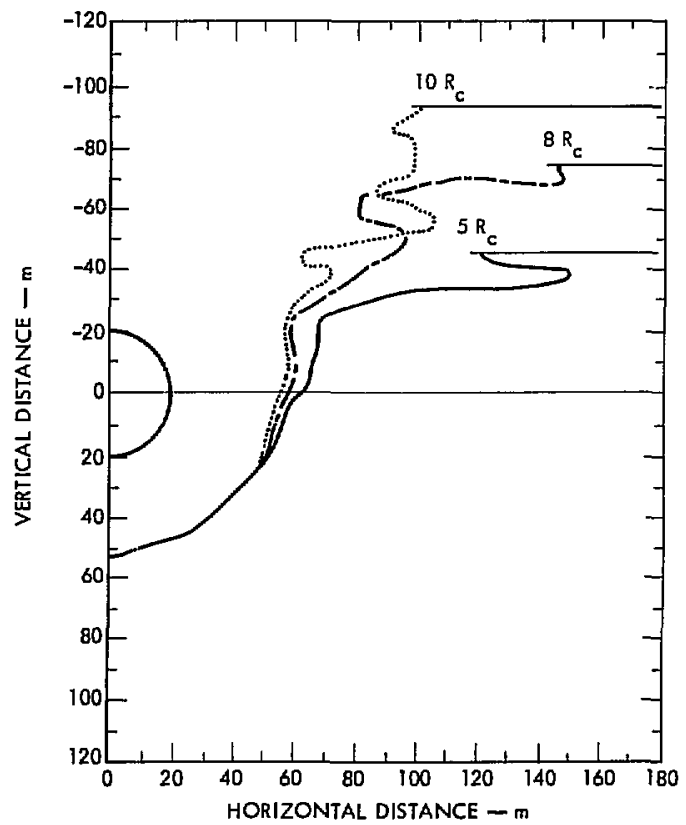

Fig. 17. Distribution of fracture as functions of spacing for simultaneous detonations, with CRX NO. $\geq 2$. 


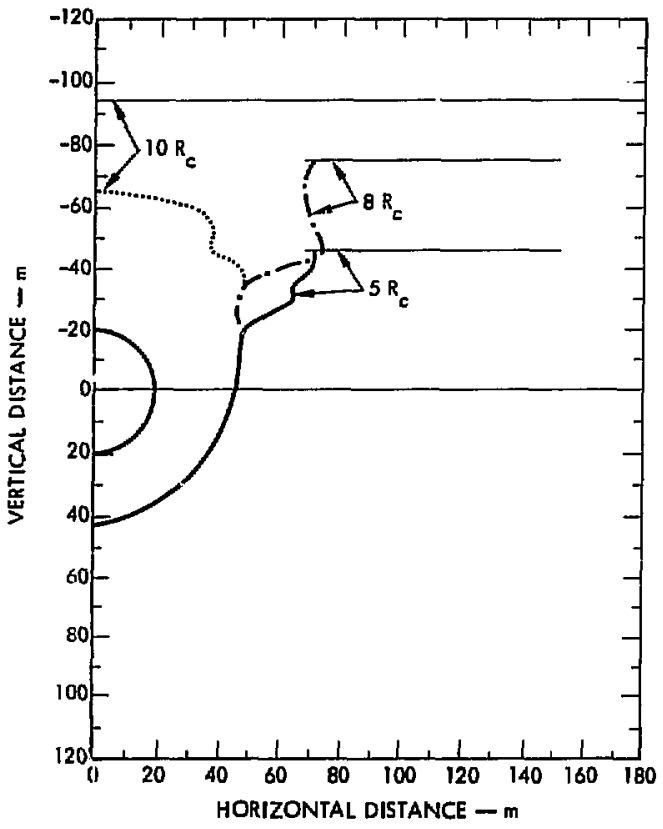

Fig. 18. Distribution of fracture as functions of spacing for simultaneous detonations, with CRX NO. 3. 
are considered, it can be seen that these volumes are slightly more sensitive to the value of $R_{c}$ that is used than was the case for CRK NO. $=1$.

\begin{tabular}{|c|c|}
\hline $\begin{array}{l}\text { EXPLOSIVE } \\
\text { SPACING }\end{array}$ & $\begin{array}{l}=2 \\
\text { VOLINE OF HIGHLY } \\
\text { FRACTURED ROCK }\end{array}$ \\
\hline $5 \mathrm{R}_{\mathrm{c}}$ & $1.4 \times 10^{6} \mathrm{~m}^{3}$ \\
\hline $8 \mathbf{R}_{\mathbf{c}}$ & $1.7 \times 10^{6} \mathrm{~m}^{3}$ \\
\hline $10 \mathbf{R}_{\mathbf{c}}$ & $1.8 \times 10^{6} \mathrm{~m}^{3}$ \\
\hline
\end{tabular}

Figure 18 shows similar plots for $C R K$ NO. $\geq 3$. Here it 15 clear that, if a permeable region is defined by a TENSOR CRK NO. $\geq 3$, then $10 R_{c}$ spacing would not produce a connection between cavities or any cracking onhancement. However, $8 R_{c}$ spacing would provide a connection with almost twice the increase in volume of cracked rock relative to the volume increase resulting from $5 \mathrm{~F}_{\mathrm{c}}$ spacing.

Thus, as in cratering, where there is an optimum depth of explosive burial, therc appears to be an optinum spacing between explosives placed in a single wellbore and detonated simultaneously to stimulate a gas-bearing sand. On the basis of these calculations, this optimun spacing appears to be equal to or greater than 8 cavity radii.

\section{COAPARISON OF CALCULATED CRACK NLMBER IITH PERMEABILITY DISTRIBUTION INFERRED FROM GAS RESERVOIR ANALYSIS}

In Section 3, the SOC calculations of Gasbuggy and Rulison were presented. The results of these cnlculations matched the measured data on fracturing, but the correlation between degree or extent of fracturing and relative increase in reservolr permeability was not as yet clear. In October 1972, Lemon and Patel [10] published the results of their gas-flow calculations for Gasbuggy. A critical input for these calculations is the persobility distribution around the nuclear chimney. The permeability distribution used in these Gasbuggy calculations was assumed to be similar to the crack-number distribution calculated by Cherry and Petersen [1]; this calculated distribution was empirically adjusted unt11 a good fit to the bottom-hole pressure history for threo wolls in the Gasbuggy area was obtalned. This correlation was made fur the perlod of production testing and pressure build-up lasting from July 1968 to May 1971.

Figure 19 shows the permeability distribution deveIoped by Lemon [10] and also the crack number from both Ref. 1 and the calculation discussed in Section 3 of this paper. Thu dectesse in permeability with distance hypothesized by Lemon and Patel [10] is very similar to the decreass in the rack number with distance reported in this work. Also, at the distance where the crack number is equal to three $(80-87 \mathrm{~m})$, Lemon and Patel noted that "a sharp increase in the permeability was required to match the performance pressure data" [10]. It would be extremely interesting if their calculations were repeated, using a smoothed permeability proftle as indicated by the dotted curve in Pig. 19 .

Figure 20 shows the crack number as a function of distance calculated for Rulison. Also shown in Fig, 20 is the variation in the permeability ratio with distance from the detonation point, as hypothesized by

\footnotetext{
${ }^{2}$ Ratio of postshot to preshot permeability of the rack.
} 


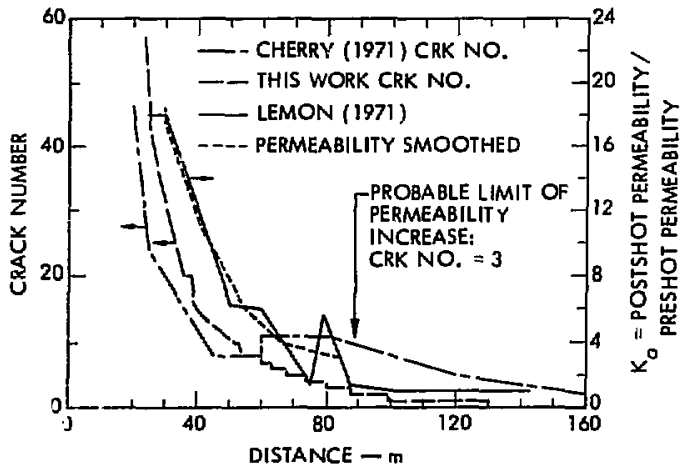

Fig, 19. Crack nurber (CRK NO.) and permeability ratto vs distance, for Gasbuggy. 


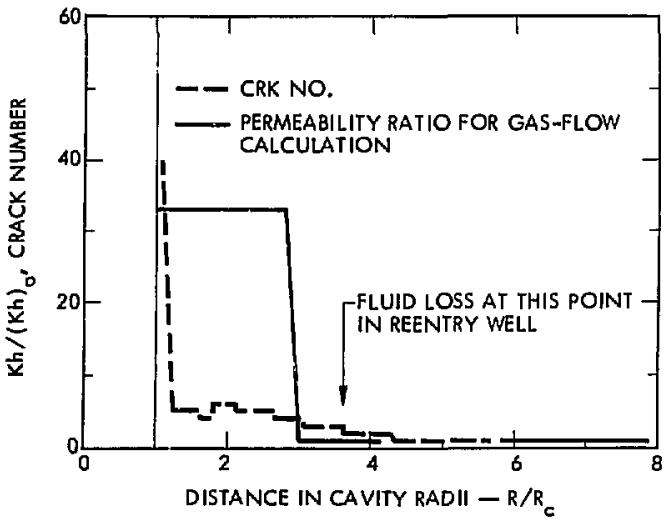

Fig. 20. Crack number (CRK No.) and permeability ratio vs distance, for Rurlison. 
Montan [11]. Notc that both crack number and permeability ratio are essentially constant, out to a distance of 2.7 cavity radii. This differs considerably from the Gasbuggy results. Figure 21 shows the gas flow from the Rulison experiment. The solid line is the calculated bottom-hole pressure as a function of time, using the permeability ratio profile shown in Fig. 20. The solid circles represent measured data. More recent measurements (not shown in Fig. 21) have indicated some divergence from the Hontan model and suggest the need for a slight adjustment in the assumed postshot in-situ permeability profile. A less rapid drop in the shotinduced permeability profile with distance from the detonation point may improve the theoretical approximation to the observed data [12]. This would bring the maximum distance of significant permeability increase more in line with the distance at which the crack number of 3 is calculated, and it would also correlate better with the distance from the detonation point at which drilling fluid loss was observed.

In both experiments, the zones calculated to have the appropriate crack number display nearly the same contour and radial extent as do the permeability profiles that best fit the experimental gas-flow data. However, between the two experiments there seens to be a considerable difference in both the magnitude of the calculated crack number and permeability ratio. Normalized to the same distance from the detonation point, the crack numbers for Gasbuggy are considerably larger than those calculated for Rulison, while just the opposite is true for the permeability profiles. The falluro envelope for Rulison al lows ductile flow at a lower sherar stress than does Gasbuggy's failure envelope. This, plus a higher overburden pressure for Rulison, would reduce the crack number close to the shat point.

Gasbuggy had many naturally existing fractures in the formation preshot; thus, the gas production has been characterized as taking place primarily by gas flow along natural joints, fractures nd bedding planes. The $(\mathrm{kh})_{0}$ factor.3 for Gasbuggy was estinated at 1000 md while this same parameter was oniy about 680 md for Rulison. Both of these facts would contribute to the reduction in enhancement of the permeability due to fracture in Gasbuggr as compared to Rulison.

The data are insufficient at the present time to attempt to develop a consistent criteria relating a crack number to a permeability magnitude. However, both experiments do indicate that a large increase in jermeability correlates well with a crack number of 3 .

\section{CONCLUSIONS}

The published versions of SOC and TENSOR represent the state of knowledge of rock mechanics that existed 4 to 5 yr ago. Since then, rapid advancenent in experimental technology and the theory of rock mechanics has been and continues to be made. In the same way, computer codes such as SOC and TENSOR are also improved and refined.

In the hands of an experienced user, these codes do simulate the lasic pitenomena caused by nuclear detonations and provide a capability for

\footnotetext{
${ }^{3}$ Formation permeability times the helght of the permeable horizon.
} 


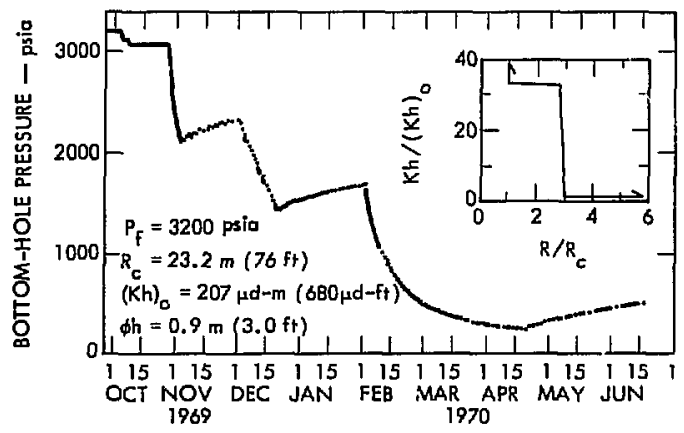

Fig, 21, Gas flow from the Rulison experiment. 
accurately predicting the exploston effects. Crack number, as used in this paper, should he regarded as a useful deftnition whose correlation with experimental data on the degree of rack fracture and pormeability increase warrants its use as a predictive indicator or these effects,

Use of the numerical techniques presented here permits the design parameters for gas-stimulation projects ustng multiplo nuclear explosives to be optimized for maximum gas production, while minimizing the number of experiments required to develop those parameters.

Sequential firing of explosives arranged in a vereical array allows the use of larger individual yields without increasing the possibility of setsinic dange relative to that predicted from an array of simultaneously detonated explosions. However, associated with sequential firing are some additional technological problems whereir further experiments are needed to give the deoired predictive capability. For lnstance, there is no reliable method of predicting the timing and rate of growti of a chimney, and the incremental time between sequential firings is dependent on the assurance that the chimey from the preceding detonation has been fully formed. None of these problems exist for simultaneous firing of explosives, ard the preliminary calculations reported here indicate that spacing between such simuleaneously fired explosives can be considerably larger than was previously envisioned.

\section{ACKNOWLEDGMENTS}

The operation of the TENSOR progran and preparation of the computer graphics by $\mathrm{Jim}$ Shaw were indispensable in the preparation of this paper. The ccntribution of Howard Tewes in helping to phrase in writing the major concepts presented here is gratefully acknowledged. Roview and comments by John Toman and Fred llol zer wore especially helpful. Special thanks also to Fran Petersen for her assistance with the $50 C$ calculations.

\section{RLFERENCES}

1. CHERIY, J. T., PETERSEN, F, L., "Whmerical simulation of stress wave propagation from underground nuclear explosives," IAEA-PL-388/15, Proceedings of a Panel on Peaceful Nuclear Explosions, Vienna. March 1970.

2. CIERRY, J. T., SACK, S., MAECHEN, G., KPANSKY, V., Two-Dimensional Stress-Induced Adiabatic Flow, Lawrence Livermore Leboratory Rept. UCRL-50987 (1970).

3. SCHOCK, R. N., HEAPD, H. C., STEPHENS, D. R., Comparison of the Nechanical Properties of Grayacke Sandstones from Soveral Nuclear Gas StImulation Sites, Lewrence Livexmore Laboratory Rept. UCRL-51261 (1972).

4. HOLZER, A., Gasbuggy in Perspective, Lawrence Livermore Laboratory Rept. UCRL-72175 (1970).

5. TERIUNE, R. W., Prediction of underground nuclear explosion effects in Wagon theel sandstone, Nucl. Technol. 15 (1972) 431.

o. KALSON, D. E., MARTIN, W., Postshot and Geological Investigation Project Gasbuggr, Lawrence Livermore Laboratory Ropt. UCRL-71354 (1968) .

7. IOLzER, F. Gasbuggy Preliminary Postshot Sumary Report, Lawrence Livermore Laboratory Rept. UCRL-5D3B6 (1968).

8. REYNOLDS, N., Jr., Trans. Amer. Nuc1. Soc. 14 (1971) 687. 
9. SCHOCK, R., STEPHENS, D., HEARD, H., Iligh Pressure Mechanical Properties of Rocks from liagon theel No. 1, Pinedale, Hyoming, Lawrence Livermore Laboratory Rept ، UCRL-50963 (1970).

10. LEMON, R. F., PATEL, H. J., The effect of nuclear stimulation on formation permeability and gas recovery at Project Gasbuggy, J. Petrol. Technol. (Oet, 1972) 1199.

11. MONTAN, D., Project Rulison Gas Flow Aralysis, Lawrence Livermore Laboratory Rept, UCRL-73263 (1971).

12. MONTAN, D., Lawrence Livernore Laboratory, priviste comaunication. 